University of Nebraska - Lincoln

DigitalCommons@University of Nebraska - Lincoln

USGS Staff -- Published Research

US Geological Survey

2014

\title{
The behavioural response of adult Petromyzon marinus to damage-released alarm and predator cues
}

I. Imre

Algoma University, istvan.imre@algomau.ca

R. T.Di Rocco

Algoma University

C. F. Belanger

Algoma University

G. E. Brown

Concordia University

N. S. Johnson

USGS Great Lakes Science Center, Hammond Bay Biological Station

Follow this and additional works at: http://digitalcommons.unl.edu/usgsstaffpub

Imre, I.; Di Rocco, R. T.; Belanger, C. F.; Brown, G. E.; and Johnson, N. S., "The behavioural response of adult Petromyzon marinus to damage-released alarm and predator cues" (2014). USGS Staff -- Published Research. 827.

http:// digitalcommons.unl.edu/usgsstaffpub/827

This Article is brought to you for free and open access by the US Geological Survey at DigitalCommons@University of Nebraska - Lincoln. It has been accepted for inclusion in USGS Staff -- Published Research by an authorized administrator of DigitalCommons@University of Nebraska - Lincoln. 
Journal of Fish Biology (2014) 84, 1490-1502

doi:10.1111/jfb.12374, available online at wileyonlinelibrary.com

\title{
The behavioural response of adult Petromyzon marinus to damage-released alarm and predator cues
}

\author{
I. ImRe*†, R. T. Di Rocco*, C. F. Belanger*, G. E. Brown $\$$ AND \\ N. S. JoHNSON§ \\ *Biology Department, Algoma University, 1520 Queen St East, Sault Ste Marie, ON, \\ P6A 2G4, Canada, $\ddagger$ Biology Department, Concordia University, 7141 Sherbrooke St West, \\ Montreal, Quebec, H4B 1R6, Canada and §USGS, Great Lakes Science Center, \\ Hammond Bay Biological Station, 11188 Ray Road, Millersburg, MI, 49759, U.S.A.
}

(Received 17 November 2013, Accepted 4 February 2014)

\begin{abstract}
Using semi-natural enclosures, this study investigated (1) whether adult sea lamprey Petromyzon marinus show avoidance of damage-released conspecific cues, damage-released heterospecific cues and predator cues and (2) whether this is a general response to injured heterospecific fishes or a specific response to injured $P$. marinus. Ten replicate groups of 10 adult $P$. marinus, separated by sex, were exposed to one of the following nine stimuli: deionized water (control), extracts prepared from adult $P$. marinus, decayed adult $P$. marinus (conspecific stimuli), sympatric white sucker Catostomus commersonii, Amazon sailfin catfish Pterygoplichthys pardalis (heterospecific stimuli), 2-phenylethylamine ( $\mathrm{PEA} \mathrm{HCl}$ ) solution, northern water snake Nerodia sipedon washing, human saliva (predator cues) and an adult P. marinus extract and human saliva combination (a damage-released conspecific cue and a predator cue). Adult $P$. marinus showed a significant avoidance response to the adult $P$. marinus extract as well as to $C$. commersonii, human saliva, PEA and the adult $P$. marinus extract and human saliva combination. For mobile $P$. marinus, the $N$. sipedon washing induced behaviour consistent with predator inspection. Exposure to the P. pardalis extract did not induce a significant avoidance response during the stimulus release period. Mobile adult female $P$. marinus showed a stronger avoidance behaviour than mobile adult male $P$. marinus in response to the adult $P$. marinus extract and the adult $P$. marinus extract and human saliva combination. The findings support the continued investigation of natural damage-released alarm cue and predator-based repellents for the behavioural manipulation of $P$. marinus populations in the Laurentian Great Lakes.
\end{abstract}

(C) 2014 The Fisheries Society of the British Isles

Key words: 2-phenylethylamine; alarm chemicals; antipredator behaviour; chemical ecology; predator-prey interactions; sea lamprey.

\section{INTRODUCTION}

Sea lamprey Petromyzon marinus L. 1758 are ectoparasitic primitive fish that invaded most of Laurentian Great Lakes in the early 20th century (Smith \& Tibbles, 1980) and precipitated large declines in a variety of native fish populations, especially lake trout Salvelinus namaycush (Walbaum 1792) (Applegate, 1951; Smith \& Tibbles, 1980; Eshenroder et al., 1992). Control of this invasive pest presently relies on lampricides

†Author to whom correspondence should be addressed. Tel.: +1 7059492301 ext. 4341; email: istvan.imre@algomau.ca 
used in tributary streams where $P$. marinus spawn (Brege et al., 2003), low-head barrier dams to prevent access to spawning grounds (Lavis et al., 2003) and trapping of adult $P$. marinus during their upstream migration (Twohey et al., 2003). Due to rising lampricide costs and an effort to diversify the control programme, the Great Lakes Fishery Commission has encouraged the development and use of alternative control methods that are effective and environmentally benign (Great Lakes Fishery Commission, 2011). One of the recently suggested approaches involve using chemosensory alarm cues as natural repellents that could be used for the behavioural manipulation of migratory phase adult $P$. marinus populations for control purposes (Imre et al., 2010).

Indeed, recent evidence suggests that $P$. marinus recognize and respond to chemosensory alarm cues. Wagner et al. (2011) demonstrated in a semi-natural experimental study that the proportion of adult $P$. marinus on the side of a laboratory stream channel scented with decaying $P$. marinus extract was significantly lower compared to the control treatment. Whether adult $P$. marinus responded to damage-released alarm cues or substances released by tissue decay was unclear, because the putrefaction extract used by Wagner et al. (2011) was a mixture of extracts from freshly killed animals as well as animals left to decay for 1, 2 and 5 days. In a follow-up, larger study, Bals \& Wagner (2012) addressed the latter uncertainty and demonstrated that adult $P$. marinus avoided the odour of freshly killed and decayed conspecifics, as well as the odour of a decayed phylogenetically close species, silver lamprey Ichthyomyzon unicuspis Hubbs \& Trautman 1937, but not the odour of freshly killed or decayed bluegill Lepomis macrochirus Rafinesque 1819, a more distantly related species. Whether the avoidance response to the odour of decayed I. unicuspis is due to similarity of alarm chemicals specific to this lineage or whether $P$. marinus had the opportunity to learn to associate these alarm chemicals with danger due to previous exposure is not clear (Pollock et al. 2003; Pollock \& Chivers 2004).

In spite of this evidence indicating that $P$. marinus responds to chemosensory alarm cues, it is unknown whether $P$. marinus shows any avoidance response to predator odours. Petromyzon marinus in its native habitat (Atlantic Ocean and tributary rivers used for spawning) falls prey to a large variety of predators, including several fish-eating bird species, northern water snake $N$. sipedon, fox Vulpes vulpes, mink Neovison vison, muskrat Ondatra zibethicus, raccoon Procyon lotor and several fish species (Scott \& Crossman, 1998; Kircheis, 2004). Even though P. marinus in the Great Lakes is not native to these ecosystems, it is likely that it retained an innate ability to respond to chemosensory cues released by potential predators (Blumstein, 2006). In addition, several of the predators (both terrestrial and aquatic) known to prey on anadromous $P$. marinus are also present in and around the Great Lakes. Curiously, only a single unpublished study has investigated the behavioural response of $P$. marinus to predator odours and suggested that $P$. marinus show an avoidance response to human saliva (R. Namespetra, unpubl. data).

The goal of this study was to investigate the behavioural response of adult $P$. marinus to damage-released alarm cues prepared from conspecific $P$. marinus (adult $P$. marinus and decayed adult $P$. marinus), heterospecific fishes [sympatric white sucker Catostomus commersonii (Lacépède 1803) and Amazon sailfin catfish Pterygoplichthys pardalis (Castelnau 1855)], three different predator cues [N. sipedon washing, human saliva and 2-phenylethylamine (PEA $\mathrm{HCl})]$ and a conspecific damage-released alarm cue and predator cue combination (adult $P$. marinus extract and human saliva mixture). Human saliva has common components with the saliva of other mammals and it is 
likely to be perceived by $P$. marinus as a chemical cue released by mammalian predators during prey handling. The $\mathrm{PEA} \mathrm{HCl}$ is a trace amine present in the urine of various mammalian predator species and has been recently shown to induce a strong avoidance response in rodents and herbivore species (Ferrero et al., 2011). The combination of conspecific damage-released alarm cue and predator cue was included because the combination carries more information and it could be perceived as a stronger threat. It was hypothesized that adult $P$. marinus are highly responsive to predatory threats using chemosensory alarm cues in their environment. It was predicted that (1) adult $P$. marinus will exhibit an avoidance response to the conspecific damage-released alarm cues and predator odours, as well as to their combination, and (2) P. marinus will avoid the sympatric $C$. commersonii extract (members of the same prey guild), but not the allopatric P. pardalis extract. As a member of the superorder Ostariophysi, C. commersonii are known to have a specialized alarm pheromone produced in the skin cells. On the other hand, the $P$. pardalis is an armoured ostariophysan that has lost the ability to produce specialized alarm substances in their skin (Helfman et al., 2009) and $P$. marinus did not have previous exposure to them. These predictions were tested in an experimental study conducted in in-ground semi-natural laboratory stream channels.

\section{MATERIALS AND METHODS}

\section{EXPERIMENTAL ANIMALS}

The US Fish and Wildlife Service provided $c .4500$ upstream migrating adult $P$. marinus collected by trapping from the Cheboygan, Ocqueoc, Manistique and St Mary's Rivers between May and July 2012. The experimental animals were held in 10001 flow-through tanks receiving chilled Lake Huron water (mean \pm S.D. temperature $=11.0 \pm 2.6^{\circ} \mathrm{C}$ and $\mathrm{pH}=7.9 \pm 0 \cdot 1$ ) at the US Geological Survey Hammond Bay Biological Station before and during the experiment. All experimental subjects were photoreversed. The holding tanks were fitted with light-emitting diode (LED) lights on timers to manage the photoperiod of the experimental subjects. Both during photoreversal and during the actual experiment, animals were kept at a 16L:8D photoperiod with lights being turned off at 0600 hours. Experimental subjects were given a minimum of 3 days to acclimate to the change in their photoperiod. The 3 day photoreversal period was considered adequate based on a laboratory study by Kleerekoper et al. (1961) who found that photoperiod can be re-established in P. marinus after exposing the experimental animals to one to two artificial diurnal light cycles.

\section{STIMULUS PREPARATION}

The stimulus solutions used in the experiment were tissue extracts from $C$. commersonii (female $n=1$; total length $\left(L_{\mathrm{T}}\right)=420 \mathrm{~mm}$; wet mass $\left(M_{\mathrm{W}}\right)=1161 \mathrm{~g}$; collected from Ocqueoc River), $P$. pardalis (female $n=1 ; L_{\mathrm{T}}=350 \mathrm{~mm} ; M_{\mathrm{W}}=332 \mathrm{~g}$; obtained from a local aquarium fish retailer), adult $P$. marinus (male $n=1 ; L_{\mathrm{T}}=480 \mathrm{~mm} ; M_{\mathrm{W}}=194 \mathrm{~g}$; female $n=1$; $L_{\mathrm{T}}=513 \mathrm{~mm} ; M_{\mathrm{W}}=235 \mathrm{~g}$; obtained from Manistique River), decayed adult $P$. marinus (male $n=1 ; L_{\mathrm{T}}=505 \mathrm{~mm} ; M_{\mathrm{W}}=269 \mathrm{~g} ;$ female $n=1 ; L_{\mathrm{T}}=494 \mathrm{~mm} ; M_{\mathrm{W}}=246 \mathrm{~g}$; collected from Manistique River), washing from $N$. sipedon (males $n=2 ; L_{\mathrm{T}}$, mean \pm S.D. $=770 \pm 14 \mathrm{~mm}$; female $n=1 ; L_{\mathrm{T}}=1180 \mathrm{~mm}$; collected around the Hammond Bay Biological Station), human saliva (collected on three occasions from several adult human males and females at the Hammond Bay Biological Station), 99\% pure PEA HCl (www.PureBulk.com), deionized water and a combination of human saliva and adult $P$. marinus extract.

Tissue donor subjects were killed with a quick blow to the head (use of experimental and tissue donor subjects was approved by the Algoma University Animal Care Committee; AUP 
\#: 2012-II-01). Tissue extracts were prepared by homogenizing the respective tissues (where applicable) in deionized water and using an aqueous solution of the filtrate as a stimulus to mimic the cue released as a result of a natural predation event. For each tissue extract solution, $160 \mathrm{~g}$ of all tissue types was collected from the anterior end of the decapitated bodies of the animals and homogenized with $800 \mathrm{ml}$ of deionized water. The homogenate was then filtered, diluted to 21 total volume with deionized water, placed in $50 \mathrm{ml}$ aliquots and stored frozen at $-20^{\circ} \mathrm{C}$. The decayed adult $P$. marinus were prepared by placing euthanized animals in 11 high-density polyethylene bottles and left to decay aerobically at ambient temperature for $48 \mathrm{~h}$. Both the fresh and the decayed adult $P$. marinus extract were prepared using equal amounts of male and female tissue.

Nerodia sipedon washing was prepared by placing all three snakes in a shallow, high-density polyethylene enclosure containing 11 of deionized water. They were kept in the enclosure for $24 \mathrm{~h}$ at room temperature. The water from the enclosure was placed in $50 \mathrm{ml}$ aliquots and stored at $-20^{\circ} \mathrm{C}$. All $N$. sipedon were released unharmed back to the habitat where they were collected.

Human saliva was collected from several males and females (employees and researchers at the Hammond Bay Biological Station). Approximately 5-15 $\mathrm{ml}$ of saliva was collected from each donor. The collected saliva was pooled and then stored at $4^{\circ} \mathrm{C}$ until needed. Saliva was kept for a maximum of $18 \mathrm{~h}$.

Water collected from the stream channels was used to dilute odorant solutions for dispensing. Five hundred millilitres of diluted solution were prepared for each replicate/treatment. The tissue extracts (C. commersonii, $P$. pardalis, adult $P$. marinus and decayed adult $P$. marinus), $N$. sipedon washing and deionized water were diluted to $5 \%$ by volume. The PEA $\mathrm{HCl}$ solution added to the stream channels was $0.32 \mathrm{M}$. Human saliva was diluted to $1 \%$ by volume. The saliva and adult $P$. marinus extract combination odorant was prepared at 1 and $5 \%$. All stimulus solutions to be dispensed into the laboratory stream channels were prepared immediately prior to use to minimize degradation.

The concentration of the tissue extract stimuli was substantially smaller than the tissue extract preparations used in a recent study (Bals \& Wagner, 2012) that examined the behavioural response of adult $P$. marinus using the same experimental system (experimental stream channels located at the Hammond Bay Biological Station, in Millersburg, Michigan, U.S.A.); less tissue was used $(160 \mathrm{~g} \mathrm{v} .220-310 \mathrm{~g})$ in at least double the rinsate:extract volume $(21 v .11 \mathrm{or}$ less) that was filtered and added to the stream channels at half the concentration (diluted to $5 v$. $10 \%$ in stream water before being delivered to the stream channels for any given replicate) than in Bals \& Wagner's (2012) study.

\section{EXPERIMENTAL PROTOCOL}

To investigate the behavioural response of adult $P$. marinus to the suite of damage-released heterospecific and conspecific cues as well as predator cues, a semi-natural experiment was performed in two parallel, in-ground laboratory stream channels located at Hammond Bay Biological Station over 11 experimental days, between 26 May and 14 July 2012. The experimental room had no windows, hence received no outside natural light. The stream channels received $0 \cdot 01 \mathrm{~m}^{3} \mathrm{~s}^{-1}$ of Lake Huron water. Ten replicates of 10 adult $P$. marinus (five groups of 10 males and five groups of 19 females) were observed for each of the nine stimuli. Male and female replicates were acclimated and tested in separate stream channels, to avoid any potential chemosensory and behavioural interactions between the sexes.

Petromyzon marinus were placed in cages (overturned baskets) separated by sex, in the two parallel laboratory stream channels, a minimum of $3 \mathrm{~h}$ before being released and observed. This allowed the future experimental subjects to acclimate to the environmental conditions characteristic to the laboratory stream channels. All replicate groups of animals to be tested in a given day of trials were deposited in the acclimation area at the same time, to avoid further disturbance. The acclimation area was several metres upstream of the experimental arena section of the laboratory stream channels. Before the start of two simultaneous replicates of a given treatment, two groups of $10 P$. marinus (of opposite sex) were moved downstream and released into experimental arena section of the two stream channels (length $\times$ width $\times$ depth $=450 \mathrm{~cm} \times 185 \mathrm{~cm} \times 20 \mathrm{~cm}$ ) by tipping the basket slowly over. Animals were given further $20 \mathrm{~min}$ to acclimate to the disturbance of being moved slowly downstream and released. After the 20 min acclimation period, 


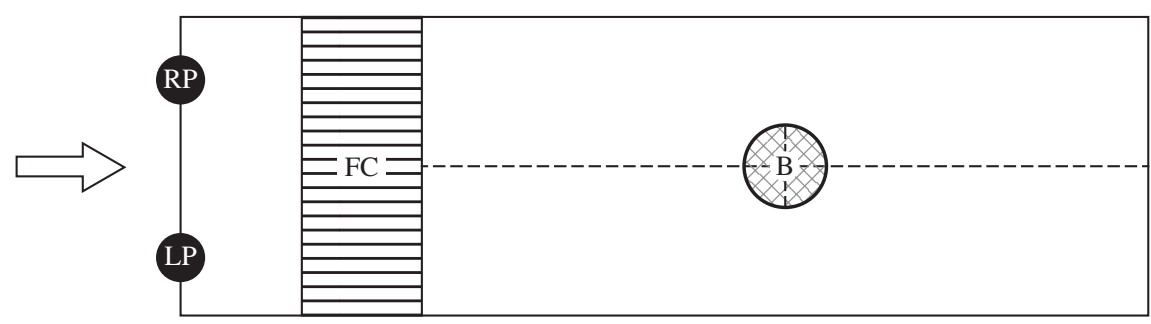

FIG. 1. View from above a laboratory stream channel $(\Leftrightarrow$, the direction of flow). The water passed through a flow conditioner (FC) made of PVC pipes to make the water flow linear and eliminate eddies. Experimental subjects were released from a basket in the centre of the stream channel (B) at the beginning of the $20 \mathrm{~min}$ acclimation period. Stimuli were dispensed from pumps on the right (RP) or left (LP) (_-_-, the middle of the laboratory stream channel).

animals were observed and their distribution was noted for $20 \mathrm{~min}$ before the release of the stimuli (pre-stimulus observation period), as well as for $20 \mathrm{~min}$ during the release of the stimuli (stimulus observation period). During the stimulus observation period, peristaltic pumps (model: Masterflex L/S 7533-20; www.masterflex.com/) located $150 \mathrm{~cm}$ upstream of the observation area pumped $20 \mathrm{ml} \mathrm{min}^{-1}$ of stimulus downstream (Fig. 1). The release side of the stimulus (left or right) in a given stream channel was regularly alternated between subsequent pairs of replicates. A recent study using the same experimental system found that the release side of the stimulus did not influence the response of the animals to stimuli (Wagner et al., 2011). After the end of a given pair of simultaneous replicates, experimental subjects were removed from the experimental arena, checked for sexual maturity and their $M_{\mathrm{W}}$ (to the nearest g; mean \pm S.D. $=229.9 \pm 49.8 \mathrm{~g}$ ) and $L_{T}$ (to the nearest $\mathrm{mm}$; mean \pm S.D. $=48.3 \pm 3.7 \mathrm{~cm}$ ) were recorded. In addition, experimental water temperature (mean \pm S.D. $=11 \cdot 3 \pm 2 \cdot 4^{\circ} \mathrm{C}$ ) was measured for every replicate trial, while $\mathrm{pH}($ mean \pm S.D. $=7 \cdot 9 \pm 0 \cdot 1)$ was measured once a day.

\section{DATA COLLECTION}

All replicates were filmed with a night-vision capable Sony video camera (model: HDR-HC9; www.sony.com/) and the footage was simultaneously recorded on DVDs with Sony video recorders (model: VRD-MC6). After the experiment ended, behavioural data were collected from DVDs. The stream channel was separated into two halves (scented and non-scented half channel, Fig. 1) and the number of moving and resting animals in each half channel was recorded every $30 \mathrm{~s}$ based on the location of the animal's head. A moving P. marinus was defined as an actively swimming individual within the experimental arena. A resting P. marinus was defined as a motionless individual latched onto a solid surface, on the bottom or on the concrete sidewall of the experimental arena.

\section{STATISTICAL ANALYSES}

Not all animals were moving in any given replicate; hence, the proportion of all P. marinus and moving $P$. marinus on the scented side was calculated for all replicates. Accordingly, the experiment generated two data sets (all P. marinus and moving P. marinus). All proportion data were normally distributed (Shapiro-Wilk test, all $W \geq 0 \cdot 977$, all $P \geq 0 \cdot 115$ ) and were transformed with an arcsine transformation.

Data were analysed with two-way ANOVA. The dependent variable was the proportion of (all or moving) P. marinus on the scented side of the laboratory stream channel, while stimulus type and sex were treated as fixed categorical factors in the model; the interaction between the stimulus type and sex was also included.

If stimulus type, sex or their interaction was significant, two further sets of post hoc analyses (one for each data set, i.e. all P. marinus and moving P. marinus) were performed to identify 
significant differences and to decompose the interaction term. Stimuli were compared to the deionized water control with one-way Dunnett's tests. If the sex or the stimulus type $\times$ sex interaction was significant, planned comparisons were performed to identify the stimuli to which adult male and female $P$. marinus showed a significantly different avoidance response. The pre-stimulus proportion data were also analysed for both datasets as above to test the assumption that the distribution of the animals did not differ before the application of the different stimuli.

All statistical tests were performed with Statistica 10 (Statsoft Inc.; www.statsoft.com/). The significance level was set at $\alpha=0 \cdot 05$.

\section{RESULTS}

The distribution of experimental subjects did not differ between treatments before the application of the respective stimuli for either all $P$. marinus (two-way ANOVA, pre-stimulus observation period, stimulus type, $F_{8,72}=0 \cdot 870, P>0 \cdot 05$; sex, $F_{1,72}=0 \cdot 161, P>0.05$; stimulus type x sex, $\left.F_{8,72}=1.584, P>0.05\right)$ or moving $P$. marinus (two-way ANOVA, pre-stimulus observation period, stimulus type, $F_{8,72}=1.095$, $P>0.05$; sex, $F_{1,72}=0 \cdot 246, P>0.05$; stimulus type $\left.\times \operatorname{sex}, F_{8,72}=1.963, P>0 \cdot 05\right)$.

The proportion of all $P$. marinus on the scented side differed across treatments during the stimulus observation period (two-way ANOVA, stimulus type, $F_{8,72}=4 \cdot 716$, $P<0 \cdot 001)$. The proportion of all $P$. marinus on the scented side exposed to $C$. commersonii extract (Dunnett's test, $P<0.05$ ), adult $P$. marinus extract (Dunnett's test, $P<0.05$ ), human saliva (Dunnett's test, $P<0.05$ ), PEA HCl (Dunnett's test, $P<0 \cdot 05$ ) and adult $P$. marinus extract and human saliva combination (Dunnett's test, $P<0 \cdot 001$ ) being significantly lower compared to the deionized water control. The decayed $P$. marinus extract (Dunnett's test, $P>0 \cdot 05$ ), the $N$. sipedon washing (Dunnett's test, $P>0.05$ ) and the $P$. pardalis extract (Dunnett's test, $P>0.05$ ) did not induce a significant change in the proportion of all $P$. marinus on the scented side during the application of stimuli, compared to the deionized water control.

On average, male and female adult $P$. marinus did not show a different distribution in response to various stimulus types (two-way ANOVA, sex, $F_{1,72}=0 \cdot 001, P>0 \cdot 05$ ); however, there were sex differences in avoidance response to some of the stimulus types (two-way ANOVA, stimulus type $\times \operatorname{sex}, F_{8,72}=2 \cdot 501, P<0 \cdot 05$ ). Planned comparisons revealed that the proportion of female adult $P$. marinus was significantly higher on the scented side in response to the $N$. sipedon washing $\left(F_{1,72}=7 \cdot 274, P<0 \cdot 01\right)$, compared to the proportion of adult male $P$. marinus on the scented side; however, it was not different from the deionized water control (Dunnett's test, $P>0 \cdot 05$ ).

Mean \pm S.D. proportions $0.66 \pm 0 \cdot 20$ and $0.68 \pm 0.20$ of all $P$. marinus were mobile during the pre-stimulus and stimulus observation periods.

Similar to the all $P$. marinus dataset, the proportion of moving $P$. marinus on the scented side differed across treatments during the stimulus observation period (two-way ANOVA, stimulus type, $F_{8,72}=18 \cdot 088, P<0 \cdot 001$, Fig. 2). The proportion of moving $P$. marinus on the scented side exposed to $C$. commersonii extract (Dunnett's test, $P<0 \cdot 01$ ), adult $P$. marinus extract (Dunnett's test, $P<0 \cdot 05$ ), human saliva (Dunnett's test, $P<0 \cdot 001$ ), PEA HCl (Dunnett's test, $P=0 \cdot 001$ ) and adult $P$. marinus extract and human saliva combination (Dunnett's test, $P<0 \cdot 001$ ) was significantly lower, compared to the deionized water control. There was a significantly higher proportion of moving $P$. marinus on the scented side in response to the $N$. 


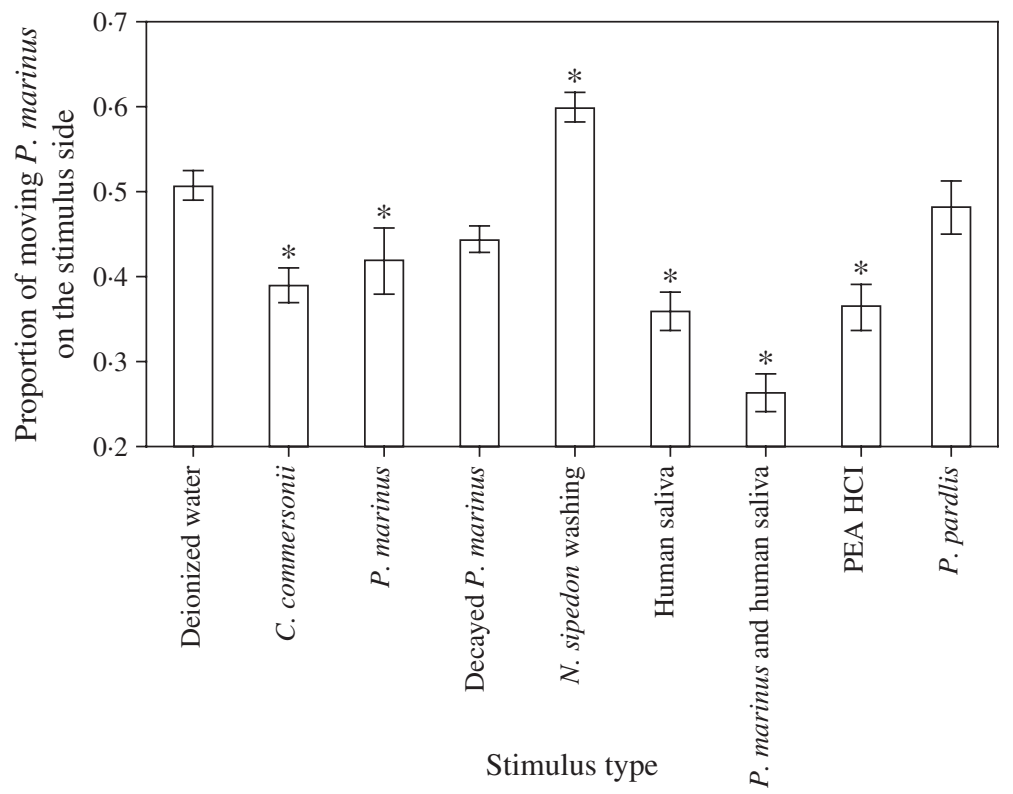

FIG. 2. Mean \pm S.E proportion of moving Petromyzon marinus on the scented side during the stimulus observation period exposed to deionized water (control), Catostomus commersonii extract, adult $P$. marinus extract, decayed adult $P$. marinus extract, Nerodia sipedon washing, human saliva, adult $P$. marinus and human saliva combination, 2-phenylethylamine $(\mathrm{PEA} \mathrm{HCl})$ solution and Pterygoplichthys pardalis extract $(n=10$ for each treatment). Responses to stimuli $(*)$ are significantly different from the deionized water control (Dunnett's test). Note that non-transformed proportion data are displayed, but the analysis was performed on arcsine-transformed proportion data.

sipedon washing (Dunnett's test, $P<0 \cdot 05)$ compared to the deionized water control. The decayed $P$. marinus extract (Dunnett's test, $P>0.05$ ) and the $P$. pardalis extract (Dunnett's test, $P>0.05$ ) did not induce a significant change in the proportion of moving $P$. marinus on the scented side during the application of stimuli, compared to the deionized water control.

Moving female adult $P$. marinus, on average, had a lower proportion on the scented side in response to various stimulus types (two-way ANOVA, sex, $F_{1,72}=7 \cdot 562$, $P<0 \cdot 01$; stimulus type $\times$ sex $\left., F_{8,72}=1.670, P>0.05\right)$ compared to moving male adult $P$. marinus. Planned comparisons showed that the proportion of moving female adult $P$. marinus was significantly lower on the scented side in response to the adult $P$. marinus extract $\left(F_{1,72}=9 \cdot 670, P<0 \cdot 01\right)$, and the adult $P$. marinus extract and human saliva combination $\left(F_{1,72}=4 \cdot 269, P<0 \cdot 05\right)$, compared to the proportion of moving adult male $P$. marinus on the scented side.

\section{DISCUSSION}

This is the first study to conclusively show that adult $P$. marinus strongly avoid a variety of predator odours, including human saliva and $\mathrm{PEA} \mathrm{HCl}$, and a human saliva and adult $P$. marinus extract combination. Adult $P$. marinus were also found to avoid adult 
$P$. marinus extract. These findings strongly support the hypothesis that $P$. marinus are highly responsive to predatory threats using chemosensory alarm cues in their environment and confirm earlier suggestions by Wagner et al. (2011) that harm avoidance is facilitated by olfaction in $P$. marinus. Furthermore, it was demonstrated that adult $P$. marinus avoided damage-released alarm cues from a sympatric but not an allopatric species of the superorder Ostariophysi.

Damage-released chemosensory alarm cues are vital in aquatic environments in terms of relaying antipredator information to a wide variety of fish species (Brown, 2003). The presence of an avoidance response by experimental adult $P$. marinus exposed to freshly killed adult $P$. marinus whole-body extract in this study suggests that $P$. marinus respond to damage-released conspecific alarm cues. The findings corroborate the conclusions of Bals \& Wagner (2012) and Pietrzakowski et al. (2013), who found that adult $P$. marinus avoided the odour of freshly killed adult and larval conspecifics.

A recent review by Imre et al. (2010) suggested that decayed adult $P$. marinus odour may function as an alarm cue for $P$. marinus. This study found that the decrease in the proportion of all adult $P$. marinus on the scented side of semi-natural stream channels exposed to decaying $P$. marinus extract was borderline significant, a behavioural response consistent with avoidance behaviour. Similarly, Wagner et al. (2011) and Bals $\&$ Wagner (2012) recently noted that adult $P$. marinus avoided the dilute odour of decaying conspecifics. Given that the strength of the avoidance response by $P$. marinus increases with the concentration of the stimulus (Bals \& Wagner 2012), it is plausible to assume that the weaker avoidance response noted in this study may be related to the lower concentration of the stimulus in this study compared to previous studies. Overall, the results of these studies suggest that $P$. marinus respond to chemicals emitted from decayed $P$. marinus and are consistent with an alarm response to alarm cues or necromones (Wagner et al., 2011).

This study also investigated the behavioural response of adult $P$. marinus to two different heterospecific stimuli, obtained from $C$. commersonii, a species sympatric with invasive $P$. marinus populations, and from $P$. pardalis that does not overlap in its distribution with $P$. marinus. Both species are members of the superorder Ostariophysi, a taxonomic group well known to harbour specialized chemicals in their skin that function as damage-released alarm cues (Pfeiffer, 1977). In contrast to C. commersonii, suckermouth armoured catfishes, including $P$. pardalis, are heavily armoured members of Ostariophysi that do not produce chemical alarm cues in their skin (Helfman et al., 2009). Petromyzon marinus showed a strong avoidance response to $C$. commersonii extract. As expected, $P$. marinus did not exhibit any avoidance of the $P$. pardalis extract. The avoidance response exhibited to the $C$. commersonii extract is surprising in the light of the fact that Bals \& Wagner (2012) clearly demonstrated no avoidance response by $P$. marinus to the damage-released alarm cues prepared from sympatric L. macrochirus. Nevertheless, the finding raises the possibility that, similar to other fish species, $P$. marinus can learn to associate alarm cues released from sympatric heterospecific individuals with the presence of predators. Heterospecific prey guild members can acquire predator recognition from being presented with a predator cue paired with alarm cues from heterospecific fishes that are a member of the same prey guild (Brown, 2003). Catostomus commersonii and P. marinus are known to co-occur (and overlap in their spawning season also) in Great Lakes tributaries (Scott \& Crossman, 1998) and can fall prey to predators inhabiting riverine environments. It is plausible to assume that $P$. marinus, perhaps as larvae, were exposed to 
damage-released alarm cues from C. commersonii, paired with olfactory predator cues. For example, Chivers et al. (1995) found that brook sticklebacks Culaea inconstans (Kirtland 1840) presented with a conspecific or fathead minnow Pimephales promelas Rafinesque 1820 extract paired with pike Esox lucius L. 1758 odour recognized the latter as a predator.

As a widespread antipredator adaptation, many prey species are averse to predator-derived odours, typically derived from skin, fur, urine, faeces and anal gland secretions (Apfelbach et al., 2005). A recent experimental study by Ferrero et al. (2011) has identified a biogenic amine PEA $\mathrm{HCl}$ as a predator cue that induced innate avoidance responses in two prey species. The authors found this chemical to be present, with enriched production, across numerous mammalian carnivores (Ferrero et al., 2011). Some of these carnivores produce over 3000-fold more of this chemical than the mammalian herbivores examined by Ferrero et al. (2011). When used as odours, biogenic amines can function as pheromones (Hashiguchi \& Nishida, 2007). Hashiguchi \& Nishida (2007) have recently identified a near-complete repertoire of trace amine-associated receptors (TAAR) genes in $P$. marinus, supporting the idea that $P$. marinus are able to recognize biogenic amines. PEA $\mathrm{HCl}$ is found in mammalian predator urine, and $P$. lotor, a known mammalian predator of $P$. marinus (Kircheis, 2004), have the highest concentration of it in their urine, compared to other North American carnivores (Ferrero et al. 2011). As expected, P. marinus presented with PEA $\mathrm{HCl}$ showed a strong avoidance response, compared to deionized water control. This finding is consistent with $P$. marinus recognizing and actively avoiding mammalian predator cues in their environment.

Fish species often approach predators, especially novel predators, to gain information about the riskiness of the predator (Brown et al., 2000), known as predator inspection behaviour. Collecting visual cues from a predator is considered to be more risky and less reliable than chemical odours (Brown et al., 2000). Compared to deionized water control, the proportion of mobile $P$. marinus increased on the side of the stream channel scented with $N$. sipedon washing, consistent with a chemically mediated predator inspection behaviour. Glowlight tetras Hemigrammus erythrozonus Durbin 1909 did inspect the odour of previously food-deprived Jack Dempsey cichlids Rocio octofasciata (Regan 1903), a novel predator odour (Brown et al., 2000). Research from other fish species clearly indicated that acquired predator recognition is dependent on a predator cue being paired with conspecific alarm cues (Brown, 2003). It is plausible to assume that $P$. marinus might be treating the $N$. sipedon washing as a novel predator cue that is being inspected because the animals do not directly associate it with predation on conspecific $P$. marinus. This assumption is supported by a study by Brown (1958) that investigated the feeding habits of the $N$. sipedon and found that $<1 \%$ of the stomachs of 207 individual snakes from central New York and northern Michigan contained $P$. marinus remains.

Mammalian saliva can also function as a warning signal. For example, human saliva mixed into sand decreased predation rates on nest of diamond-backed terrapin Malaclemys terrapin by P. lotor (Burke et al., 2005). Anecdotal observations by $P$. marinus control agents routinely indicated that the presence of human saliva in water induces strong fright responses by captive $P$. marinus. In addition, $R$. Namespetra (unpubl. data) found that $P$. marinus exhibited strong signs of distress and actively avoided undiluted human saliva when compared to river water control. The present experiment indicated that the proportion of $P$. marinus on the side of stream channels 
scented with human saliva was significantly lower compared to a deionized water control. This finding is consistent with the hypothesis that $P$. marinus perceive human saliva as a mammalian predator cue, but further research is needed to ascertain what are the active ingredients of saliva that induce an avoidance response.

Adult $P$. marinus in this study showed the strongest apparent avoidance response to a combination of a mammalian predator cue (human saliva) and damage-released conspecific alarm cue (adult $P$. marinus extract). This result is consistent with the expectation that conspecific alarm cues coupled with predator cues should induce a stronger avoidance response than either of these alarm cues alone (i.e. sensory complementation; Elvidge et al. 2013), because the combination carries more information (identifies not only that a conspecific individual was predated upon but also reveals the identity of the predator) and as such it could be perceived as higher level of threat (Ferrari et al. 2008; Kim et al., 2009; Leduc et al. 2010). Indeed, H. erythrozonus, for example, took a longer time to initiate inspection, inspected in smaller groups and remained a larger distance from the odour source derived from $H$. erythrozonus-fed $R$. octofasciata, compared to food deprived $R$. octofasciata or $R$. octofasciata that were fed a different species of fish (Brown et al., 2000). Further research should address the distinction in avoidance response strength to combined, compared to single cues and investigate the potential interaction between increased overall alarm cue concentration (additive effect) and cue type (synergistic effect).

Mobile adult female $P$. marinus showed stronger avoidance of the adult $P$. marinus extract as well as the adult $P$. marinus extract and human saliva combination than adult male $P$. marinus in the study. This finding is in contrast with that of Bals \& Wagner (2012), who did not find differences in avoidance behaviour between sexes when exposed to damage-released alarm cues. A recent study by Pietrzakowski et al. (2013) found that, when presented with the odour of freshly killed P. marinus larvae, adult female $P$. marinus swam significantly longer than adult male $P$. marinus, presumably to avoid predation. The findings of Pietrzakowski et al. (2013) and this study suggest that females may be less willing to take risks than males. As females have a larger reproductive investment, they may be selected to better avoid predators until they reproduce. Intersexual differences in predator avoidance behaviour are well documented in other fish species. For example, dominant male darkedged splitfin Girardinichthys multiradiatus (Meek 1904) approach predators more often than females (Macías Garcia et al., 1994) and are more frequently attacked and consumed by predators (Macías Garcia et al., 1998).

As a next step, further research should explore the effect of the concentration of predator cues and combination cues (conspecific damage-released alarm cues and predator cues) on the strength of avoidance behaviour, potential synergistic effect of combining different alarm cues as well as the efficiency of application of the above stimuli in the wild, where $P$. marinus of both sexes migrate in streams that are variable in size, temperature, microhabitat type and flow conditions. In addition, almost all the above cues are a cocktail of a wide array of chemicals, so identifying the active ingredients is instrumental for making the application of these repellents both more effective for behavioural manipulation as well as more appropriate for industrial scale production.

In conclusion, $P$. marinus showed an avoidance response to adult $P$. marinus extract, sympatric heterospecific alarm cues $(C$. commersonii extract) as well as predator cues, like human saliva (mammalian predator cue) and PEA $\mathrm{HCl}$ (a chemical present in 
the urine of a large number of mammalian carnivores) as well as a combination of damage-released conspecific alarm cue and predator cue (adult $P$. marinus extract plus human saliva). Nerodia sipedon washing induced a behavioural response by mobile adult $P$. marinus consistent with predator inspection. $P$. marinus showed no response to tissue extract from $P$. pardalis, an exotic catfish. Mobile adult female $P$. marinus showed a stronger avoidance behaviour than mobile adult male $P$. marinus in response to the adult $P$. marinus extract and the adult $P$. marinus extract and human saliva combination. Overall, as suggested by Imre et al. (2010), damage-released alarm cues now present a realistic potential of being used as a tool in controlling $P$. marinus populations in the American Great Lakes.

The authors are grateful to the Hammond Bay Biological Station for their logistical and housing support, especially to M. Hansen and K. Slaght. Special thanks are due to M. Wagner, J. Bals and T. Meckley for generously allowing us to use their video camera and video recording equipment and for putting up with our questions over the summer months. R. Pietrzakowski and J. Sauvé helped with data collection from DVDs. Thanks are due to all the personnel working at the Station who generously donated human saliva for our research. This research was supported by grants from the Great Lakes Fishery Commission, Northern Ontario Heritage Fund Corporation and the National Sciences and Engineering Research Council Undergraduate Summer Research Assistant Program. The authors also thank two anonymous referees for their constructive comments. This article is contribution number 1822 of the Great Lakes Science Center.

\section{References}

Apfelbach, R., Blanchard, C. D., Blanchard, R. J., Hayes, R. A. \& McGregor, I. S. (2005). The effects of predator odors in mammalian prey species: a review of laboratory and field studies. Neuroscience and Biobehavioral Reviews 29, 1123-1144.

Applegate, V. C. (1951). The sea lamprey in the Great Lakes. The Scientific Monthly 72, $275-281$.

Bals, J. D. \& Wagner, C. M. (2012). Behavioural responses of sea lamprey (Petromyzon marinus) to a putative alarm cue derived from conspecific and heterospecific sources. Behaviour 149, 901-923.

Blumstein, D. (2006). The multipredator hypothesis and the evolutionary persistence of antipredator behavior. Ethology 112, 209-217.

Brege, D. C., Davis, D. M., Genovese, J. M., McAuley, T. C., Stephens, B. E. \& Westman, R. W. (2003). Factors responsible for the reduction in quantity of the lampricide, TFM, applied annually in streams tributary to the Great Lakes from 1979 to 1999. Journal of Great Lakes Research 29(Suppl. 1), 500-509.

Brown, E. E. (1958). Feeding habits of the Northern water snake Natrix sipedon sipedon Linnaeus. Zoologica 43, 55-71.

Brown, G. E. (2003). Learning about danger: chemical alarm cues and local risk assessment in prey fishes. Fish and Fisheries 4, 227-234.

Brown, G. E., Paige, J. A. \& Godin, J.-G. J. (2000). Chemically mediated predator inspection behavior in the absence of predator visual cues by a characin fish. Animal Behaviour 60, $315-321$.

Burke, R. L., Schneider, C. M. \& Dolinger, M. T. (2005). Cues used by raccoons to find turtle nests: effects of flags, human scent, and diamond-backed terrapin sign. Journal of Herpetology 39, 312-315.

Chivers, D. P., Brown, G. E. \& Smith, R. J. F. (1995). Acquired recognition of chemical stimuli from pike, Esox lucius, by brook sticklebacks, Culaea inconstans (Osteichthyes, Gasterosteidae). Ethology 99, 234-242.

Elvidge, C. K., Macnaughton, C. J. \& Brown, G. E. (2013). Sensory complementation and antipredator behavioural compensation in acid-impacted juvenile Atlantic salmon. Oecologia 172, 69-78. 
Eshenroder, R. L., Coble, D. W., Bruesewitz, R. E., Fratt, T. W. \& Scheirer, J. W. (1992). Decline of lake trout in Lake Huron. Transactions of the American Fisheries Society 121, 548-554.

Ferrero, D. M., Lemon, J. K., Fluegge, D., Pashkovski, S. L., Korzan, W. J., Datta, S. R., Spehr, M., Fendt, M. \& Liberles, S. D. (2011). Detection and avoidance of a carnivore odor by prey. Proceedings of the National Academy of Sciences 108, 11235-11240.

Ferrari, M. C. O., Vavrek, M. A., Elvidge, C. K., Fridman, B., Chivers, D. P. \& Brown, G. E. (2008). Sensory complementation and the acquisition of predator recognition by salmonid fishes. Behavioral Ecology and Sociobiology 63, 113-121.

Great Lakes Fishery Commission (2011). Strategic Vision of the Great Lakes Fishery Commission 2011-2020. Ann Arbor, MI: Great Lakes Fishery Commission.

Hashiguchi, Y. \& Nishida, M. (2007). Evolution of trace amine-associated receptor (TAAR) gene family in vertebrates: lineage-specific expansions and degradations of a second class of vertebrate chemosensory receptors expressed in the olfactory epithelium. Molecular Biology and Evolution 24, 2099-2107.

Helfman, G., Collette, B. B., Facey, D. E. \& Bowen, B. W. (2009). The Diversity of Fishes: Biology, Evolution and Ecology, 2nd edn. Chichester: Wiley-Blackwell.

Imre, I., Brown, G. E., Bergstedt, R. A. \& McDonald, R. (2010). Use of chemosensory cues as repellents for sea lamprey: Potential directions for population management. Journal of Great Lakes Research 36, 790-793.

Kim, J.-W., Brown, G. E., Dolinsek, I. J., Brodeur, N. N., Leduc, A. O. H. C. \& Grant, J. W. A. (2009). Combined effects of chemical and visual information in eliciting antipredator behaviour in juvenile Atlantic salmon Salmo salar. Journal of Fish Biology 74, $1280-1290$.

Kleerekoper, H., Tayler, G. \& Wilton, R. (1961). Diurnal periodicity in the activity of Petromyzon marinus and the effects of chemical stimulation. Transactions of the American Fisheries Society 90, 73-78.

Lavis, D. S., Hallett, A., Koon, E. M. \& McAuley, T. C. (2003). History of and advances in barriers as an alternative method to suppress sea lampreys in the Great Lakes. Journal of Great Lakes Research 29(Suppl. 1), 362-372.

Leduc, A. O. H. C., Kim, J.-W., Macnaughton, C. J. \& Brown, G. E. (2010). Sensory complement model helps to predict diel alarm response patterns in juvenile Atlantic salmon (Salmo salar) under natural conditions. Canadian Journal of Zoology 88, 398-403.

Macías Garcia, C., Jimenez, G. \& Contreras, B. (1994). Correlational evidence of a sexually-selected handicap. Behavioral Ecology and Sociobiology 35, 253-259.

Macías Garcia, C., Saborío, E. \& Berea, C. (1998). Does male-biased predation lead to male scarcity in vivaparous fish? Journal of Fish Biology 53(Suppl. A), 104-117.

Pfeiffer, W. (1977). The distribution and fright reaction and alarm substance cells in fishes. Copeia 1977, 653-665.

Pietrzakowski, R., Imre, I. \& Brown, G. E. (2013). The behavioural response of migratory sea lamprey (Petromyzon marinus) to potential damage-released larval and migratory chemical alarm cues. Journal of Great Lakes Research 39, 234-238.

Pollock, M. S., Chivers, D. P., Mirza, R. S. \& Wisenden, B. D. (2003). Fathead minnows, Pimephales promelas, learn to recognize chemical alarm cues of introduced brook stickleback, Culaea inconstans. Environmental Biology of Fishes 66, 313-319.

Pollock, M. S. \& Chivers, D. P. (2004). The effects of density on the learned recognition of heterospecific alarm cues. Ethology 110, 341-349.

Scott, W. B. \& Crossman, E. J. (1998). Freshwater Fishes of Canada. Oakville, ON: Galt House Publications Ltd..

Smith, B. R. \& Tibbles, J. J. (1980). Sea lamprey (Petromyzon marinus) in Lakes Huron, Michigan and Superior: history of invasion and control 1936-78. Canadian Journal of Fisheries and Aquatic Sciences 37, 1780-1801.

Twohey, M. B., Heinrich, J. W., Seelye, J. G., Fredricks, K. T., Bergstedt, R. A., Kaye, C. A., Scholefield, R. J., McDonald, R. B. \& Christie, C. G. (2003). The sterile male release technique in Great Lakes sea lamprey management. Journal of Great Lakes Research 29(Suppl. 1), 410-423. 
Wagner, C. M., Stroud, E. M. \& Meckley, T. D. (2011). A deathly odor suggests a new sustainable tool for controlling a costly invasive species. Canadian Journal of Fisheries and Aquatic Sciences 68, 1157-1160.

\section{Electronic Reference}

Kircheis, F. W. (2004). Sea lamprey Petromyzon marinus Linnaeus 1758. Environmental Consultant Report for the United States Fish and Wildlife Service. Available at http://ibrarian.net/navon/paper/SEA_LAMPREY_Petromyzon_marinus_Linnaeus_ 1758.pdf?paperid=10453247/ (accessed on 4 February 2014). 